\title{
Rational Design of Hierarchical MnO@N-doped Carbon Nanowires as a High-Performance Anode for Lithium-Ion Batteries
}

\author{
Xiaoming $X u^{*}$, Renzheng Li, Huanhuan Li, Donghai Hu, Jiaqi Fu
}

School of Automotive and Traffic Engineering, Jiangsu University, Zhenjiang, China, 212013

*E-mail: xuxiaoming3777@163.com

doi: $10.20964 / 2018.07 .57$

Received: 16 March 2018 / Accepted: 10 May 2018 / Published: 5 June 2018

\begin{abstract}
A facile synthesis strategy for hierarchical MnO@N-doped carbon nanowires was developed using a single in situ pyrolysis of Mn-based coordination polymers. Core-shell MnO@N-doped carbon building blocks are interconnected into a mesoporous nanowire. The artificial nanocomposite facilitates fast transport of $\mathrm{Li}^{+}$ions and electrons and buffers the $\mathrm{MnO}$ volume change during $\mathrm{Li}$ insertion/extraction processes. As a consequence, hierarchical $\mathrm{MnO} @ \mathrm{~N}$-doped carbon nanowires display a promising electrochemical performance, such as a high reversible capacity, excellent cycling stability and rate capability, as an anode material for lithium-ion batteries.
\end{abstract}

Keywords: $\mathrm{MnO}$; N-doped carbon; anode material; lithium-ion battery; energy storage and conversion

\section{$\underline{\text { FULL TEXT }}$}

(C) 2018 The Authors. Published by ESG (www.electrochemsci.org). This article is an open access article distributed under the terms and conditions of the Creative Commons Attribution license (http://creativecommons.org/licenses/by/4.0/). 